\title{
Recent Work in Cataloging and Classification, 2000-2002
}

\section{Kyung-Sun Kim}

This article provides a review of cataloging and classification publications that appeared in the last two years. The review considers the papers in two categories. Cataloging Theories and Practices covers descriptive cataloging, authority control, classification, subject cataloging, cataloging nonbook materials, electronic resources and metadata, and international cooperation. The second section covers other issues related to cataloging, including management, and education and training. Throughout the review, the author identifies trends and important developments in the area of cataloging and classification.

Cataloging literature published from late 2000 through early 2002 reflects

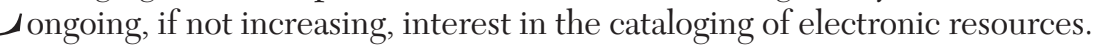
Numerous meetings and newly formed interest groups on this topic have been convened while cataloging rules and standards have undergone significant revisions (McKiernan 2002a; 2002b). Another recognizable characteristic of this body of literature is its international scope. In a number of papers, issues on bibliographic control and international cooperation have been discussed to facilitate the exchange and retrieval of bibliographic information at the international level.

This article will briefly describe cataloging and classification publishing highlights of the last two years through a review of the literature. This review is limited to print materials and a few Web resources. The reviewed papers are organized and presented in two parts. Part one focuses on cataloging theories and practices, and consists of the following categories: (1) descriptive cataloging, (2) authority control, (3) classification, (4) subject cataloging, (5) cataloging nonbook materials, (6) electronic resources and metadata, and (7) international cooperation. Part two covers other cataloging-related issues, such as management and education and training.

\section{Cataloging Theory and Practice Descriptive Cataloging}

For the last two years, a significant part of the rules and standards used for descriptive cataloging have been revised, mainly due to ever-changing technology generating changes at a rapid pace. In this section, recent revisions made in International Standard Bibliographic Description (ISBD), Anglo-American Cataloging Rules (AACR), and MAchine Readable Cataloging (MARC) are summarized. Impacts of Fundamental Requirements for Bibliographic Records 
(FRBR), which the International Federation of Library Associations (IFLA) introduced as early as 1997, are also discussed, followed by some problems in descriptive cataloging.

\section{Rules and Standards}

AACR has been continually modified to incorporate revisions necessitated by a changing technological environment since the 1967 publication of the first edition. Manning (2000) provides a brief history of AACR and summarizes recent developments in the cataloging rules, including those resulting from the advent of the Internet. Redefining "seriality" and restructuring bibliographic data based on an entity-relationship model are examples of the recent developments.

In late 2002, the 2002 revision of AACR2 (AACR2r 2002), incorporating all the amendments in 1999 and 2001 and also including additional revisions finalized in 2002, was published in loose-leaf format for updating. Three chapters of the AACR2r (2002) have undergone significant changes: chapters 3,9 , and 12. Chapter 3 for Cartographic Materials has changed to include rules for cartographic materials in electronic form and other updated rules. Chapter 9, whose title was changed from "Computer Files" to "Electronic Resources," now contains rules aligned with the International Standard Bibliographic Description for Electronic Resources (ISBD(ER)). The provision of a distinction between direct access and remote access to electronic resources is an example of such alignment. Chapter 12, formerly "Serials" but now titled "Continuing Resources," has been revised to accommodate "seriality" in the rules. The rules have been expanded to include successively issued resources, ongoing integrating resources (e.g., updating loose-leafs, updating Web sites), and some categories of finite resources (e.g., reprints of serials, finite integrating resources). In addition, AACR2r (2002) includes other updated rules and a new glossary.

ISBD, an international standard for the form and content of bibliographic description, also has experienced a significant adjustment to incorporate recent changes in the bibliographic world. ISBD(ER), revised from $\operatorname{ISBD}(\mathrm{CF})$ for Computer Files, was published in 1997. This change resulted in the revision of chapter 9 of AACR and was incorporated in AACR2r (2002). ISBD(CR) for Serials and Other Continuing Resources, revised from $\operatorname{ISBD}(\mathrm{S})$ for Serials, was issued in 2002 and incorporated in AACR2r (2002). Although changes are not as drastic as in $\operatorname{ISBD}(\mathrm{CR})$ and $\operatorname{ISBD}(\mathrm{ER})$, $\operatorname{ISBD}(\mathrm{M})$ for Monographic Materials also was revised in 2002. Hirons, Darling, and Robertson (2001) and Hawkins (2001) describe amendments and progress in AACR2 and $\operatorname{ISBD}(S)$ made until 2001. They report the status of the harmonization of
AACR, ISSN, and ISBD $(S)$ and discuss what has been proposed to revise AACR2.

MARC, standards for the representation and communication of bibliographic and related information in machine-readable form, has undergone some important changes. MARC21, the first harmonized version of USMARC and CANMARC, was published in 1999. Discussing differences and similarities among USMARC, CANMARC, and UKMARC, McCallum (2000) describes the process of USMARC and CANMARC harmonization and their increasing compatibility with UKMARC. Comparing MARC with Extensible Markup Language (XML), Johnson (2001) remarks that despite the great potential of XML, MARC is still an important and broadly accepted encoding system. Fiander (2001) recognizes the usefulness of transliterating the MARC fields and subfields directly into an XML Document Type Definition (DTD), preserving the structure of MARC exactly. However, he also argues that this kind of effort would fail to take advantage of XML's facilities despite some advantages of the direct translation (e.g., easy conversion between MARC and Standard Generalized Markup Language (SGML)). He urges that before converting from MARC to XML, fundamental changes should be considered, such as redoing AACR2r based on IFLA's FRBR. Problems of MARC, including its rigidity and internal irregularities, will need to be solved before migrating away from MARC to a newer data format (Fiander 2001).

\section{Models and Theories}

FRBR was first introduced by IFLA in 1997 and published in the following year. This model is used for grouping entities dealt with in library catalogs and for delineating the functions performed by the bibliographic record using the entity-relationship analysis technique. According to FRBR, a bibliographic record is defined as the aggregate of data that is associated with entities that are key objects of interest to users. Three groups of entities exist that are useful to users. The first group contains four entities: work, expression, manifestation, and item. The second group includes entities responsible for the intellectual or artistic contents, the production, or ownership of the entities in the first group. Finally, the third group comprises entities representing concepts, objects, events, and places. The functions of the bibliographic records are defined based on the tasks that users perform while searching library catalogs. Those functions include finding, identifying, selecting, and obtaining. FRBR requires identifying the attributes associated with each entity and the relationships between entities important to users, describing logical relationships among the various entities, and defining the relationships associated with the four primary entities (work, expression, manifestation, item) 
and then mapping the attributes and the four user tasks (finding, identifying, selecting, and obtaining). Depending on their importance to users, the attributes and relationships are rated, which is used for identifying the essential components of a bibliographic record.

Madison (2000) and Le Boeuf (2001) provide good descriptions of FRBR and discuss how FRBR can be implemented in practice in order to provide access to bibliographic records in a more orderly and logical fashion. Although it is yet to be implemented, FRBR has been receiving a great deal of attention from many countries, including the United States. Hickey, O'Neill, and Toves (2002) explain what the Online Computer Library Center (OCLC) is doing in order to implement IFLA's FRBR. In their paper, they describe OCLC's efforts in grouping the existing bibliographic records based on the FRBR model, by using an algorithm.

\section{Problems}

With the globalization of bibliographic databases, an increasing number of foreign language books are becoming available in libraries. Since having catalogers with multiple language expertise is seldom possible, many libraries rely on cooperative cataloging when cataloging foreign language books. From OCLC's catalog, for example, libraries can retrieve bibliographic records for the foreign books and use them with some modifications in their local libraries. Kellsey (2001; 2002) and Shedenhelm and Burk (2001) examine vendors' records for Italian, Spanish, and other European language monographs and report that many of the vendor records are of poor quality (e.g., errors, missing information, lack of authority control). Both papers found that many records for foreign language books available in OCLC's database are created by vendors. As the quality of the vendors' records is usually poor, this results in numerous duplicates and many other problems. The authors call for more OCLC intervention and increased international cooperation to improve the usefulness of vendor records to catalogers.

Another problem associated with cataloging foreign language books is Romanization. When cataloging foreign books in non-Roman scripts, catalogers must transliterate bibliographic data, such as titles or names of authors in the Roman (Latin) scripts, using a Romanization system. Wang (2000) indicates that the form of a person's name in records can vary significantly depending on the Romanization system used, and that this causes serious problems. Arsenault (2001) compares different Romanization systems for Chinese language (e.g., Wade-Giles, Pinyin) and suggests a system that can facilitate the retrieval of Chinese language materials better than others.

Regardless of the language used, books containing errors made by publishers create a challenge. Both
Bowman (2001) and Beall (2001) address the issue related to cataloging books with publishers' errors. Beall (2001) points out that the lack of guidelines in using error indicators has led to inconsistent cataloging practices and also impedes efficient retrieval of items.

\section{Authority Control}

Authority control is one of the most complex and tedious tasks in cataloging. While the internationalization of bibliographic databases has made the process more challenging, new technologies have offered new solutions to, or alternative ways of, authority control. This section first reviews studies on authority control problems found in names in non-Roman alphabets, and then those on international authority control efforts. Finally, those offering new solutions to authority control are reviewed and discussed.

With regard to the authority control of names in nonRoman scripts, Wang (2000) discusses problems with Chinese names. She points out that the form of a person's name in authority records can vary depending on the Romanization system used and the language and dialect used by the person. Variant names for the same person could cause a serious problem in authority control and also in bibliographic retrieval. Wang (2000) presents sample cases with similar problems and suggests that catalogers should include appropriate notes in the record to clarify situations. Addressing problems that Romanization can cause, Weinberg and Aliprand (2002) suggest that as the uniqueness of a heading in a source script is lost through Romanization, the uniqueness must be restored via the use of a qualification.

With globalization, an increasing amount of collaboration also has been achieved at the international level. Tillet (2000) reports a variety of international authority control efforts, including IFLA's Guidelines for Authority and Reference Entries (GARE), Minimum Level Authority Records (MLAR) Working Group's recommendation on a minimal set of essential data elements to be included in any national authority record, Project AUTHOR (a shared set of national authority files of five European countries), and so on. Heijligers (2001) describes the efforts of the Working Group on Form and Structure of Corporate Headings (FSCH) in establishing a worldwide uniform heading for corporate bodies. Recognizing and reconfirming the extreme difficulty in this, he suggests an alternative solution to the problem. Instead of establishing one authoritative form of name for every corporate body, providing an online overview of all relevant name forms pertaining to a particular body, by making use of the combination of modern computer technologies and the Internet, might be more efficient. This kind of system will help catalogers in differ- 
ent countries select one as an authorized form, based on their users' needs.

In order to make the authority control process easier, especially for corporate body names, Ellero (2002) suggests that the Web can be used as a reference source for such names since many companies have their own Web sites and usually keep the sites current. She calls for more flexible and practical authority control, which will also help users find information more easily.

To facilitate information retrieval by users, Ayres (2001) argues that cross-references should be made completely, not selectively. Since most cross-referencing is done only partially, users often fail to retrieve all the related items on online catalogs. Ayres (2001) underscores the importance of comprehensive cross-reference in information retrieval. Another way of helping users search, Horn (2002) suggests, would be to make authority files available to users through the Online Public Access Catalog (OPAC). Her observation is that most users do not understand differences between keyword searches and subject searches on OPACs. She believes that making authority files accessible will help users differentiate keyword and subject searches and improve their searches on OPACs.

\section{Classification}

The recent literature on library classification falls into two categories: problems of existing classification systems, including cultural bias, and the wide application of the systems. This section starts with problems found in classification systems and then describes where and how classification systems are applied.

As some American classification systems are introduced to and used in an increasing number of foreign countries, more people have become aware of the problems that the classification systems have. One of the fundamental problems of the systems is cultural bias. Dewey Decimal Classification (DDC) and Library of Congress Classification (LCC) are the library classification systems most commonly used worldwide, including Latin America (Martinez-Arellano and Yanez Garrido 2000). They were developed in the United States in the late nineteenth century, originally for organizing collections for users in the United States. Naturally, the classification systems are heavily influenced by Western culture, and their emphasis is on the United States and some European countries. For example, in DDC, Christianity is privileged in the religion class (Rafferty 2001). In the main class for religion (200-299), divisions from 230 through 289 are dedicated to Christianity while other religions are compacted in 290 to 299. In LCC, the American emphasis is evident in geographic arrangements. Algier (2001) has noticed such bias in LCC and suggests that the Library of Congress should put more effort into providing accurate and up-to-date classification numbers and geographic headings for Caribbean and other countries in the world.

Suggestions that Hope Olson (2001) and Begthol (2002) made for fixing the cultural bias problem in classification are deep-rooted. According to Olson (2001), most classification systems reflect the society's cultural orientation. Problems with classifications begin here-what a classification system defines as the same is culturally grounded, and classification, as we practice it, creates a hierarchy of sameness. The DDC, for example, puts a priority on a certain kind of sameness, with the result that materials with other kinds of sameness are scattered among many classes, even when the latter kinds of likeness may be more important and should be so classified. Because of DDC's priority on the language, works of Canadian literature in different languages are classed under 810 (English literature), 840 (French literature), etc., instead of being under one class (Canadian literature). To fix this kind of problem, Olson (2001) suggests making classification systems more flexible by allowing different ways of applying the system, using an unconventional notation system, varying the citation order, and so on. In an attempt to make DDC more hospitable to other cultures without Christian dominance, Oh and Yeo (2001) suggest alternative ways of classifying materials in religion using DDC. Several options are explored to accommodate different distributions of religions in Asian countries.

Beghtol (2002) proposes the theoretical concept of cultural hospitality with user-choice mechanisms as a theoretical foundation for establishing methods of developing culture-neutral systems and theories. The concept of cultural hospitality with user-choice options appears to make it theoretically possible for people to think and act globally and, simultaneously, to act locally and individually.

Despite its cultural bias, DDC seems to be one of the popular classification systems used for organizing Web resources. Vizine-Goetz (2001b) introduces some projects that use DDC to organize and provide subject access to their databases. Mitchell (2001) also confirms the widespread application of the DDC throughout the world. Saeed and Chaudhry (2001) review several Web sites where resources are organized based on DDC and other classification systems and discuss the potential of DDC for an effective organization of Internet resources. DDC also is used along with other systems in order to make the organization of information easier. Saeed and Chaudhry (2002) describe a project in which DDC, terms from the DDC schedule, and terms from the Institute of Electrical and Electronics Engineers (IEEE) Web thesaurus are integrated to build a tool for a categorization that facilitates browsing of information resources in an electronic environment. Similarly, Godby and Vizine-Goetz (2000) introduce some current 
research including a mapping of the Engineering Index (EI) thesaurus, Library of Congress Subject Headings (LCSH), and DDC to test automatic classification.

For the last two years, some efforts have been made to render DDC easier to use. In 2000, WebDewey in CORC (OCLC's Cooperative Online Resource Catalog, now part of OCLC Connexion) was introduced. In early 2002, WebDewey, and People, Place and Things were released along with Abridged DDC and Sears List of Subject Headings (Lawson 2001). People, Place and Things is designed to help users find the right places to browse for information organized by DDC. It provides a list of more than 50,000 LCSHs paired with corresponding DDC numbers. Crawford (2001) offers more details on how the list was compiled using records from OCLC's World Cat.

Compared to DDC, LCC seems to have received less attention from catalogers. In her paper on the classification of publications from an educational institution, Shelton (2000) addresses one of the LCC's problems. In the class L in LCC, for example, the Library of Congress's table assigns only one number to smaller institutions, but several numbers to bigger ones. As only one number can be used for a smaller institution, libraries that have many publications from the one-number institutions face difficulties in assigning more meaningful and unique call numbers. Shelton (2000) illustrates how her library deals with the problem to improve the retrieval of such institution's publications.

Finally, for those who use and study library classification systems, understanding basic concepts and terms used in classification is important and helpful. Satija (2000) provides good definitions of some key terminology used in classification and clarifies the differences in terms that often are used in a confusing way.

\section{Subject Cataloging}

The field has seen several interesting developments in providing subject access to bibliographic items via controlled vocabulary. Form subdivision has been recognized as an independent subdivision and is coded differently from general subdivisions in practice, which will enable users to search items by form. Faceted subject headings have been introduced to make subject searches easier. Projects mapping subject headings in different systems, even in different languages, have been launched to improve information retrieval. This section reviews literature on these issues and some problems related to subject cataloging.

\section{Form Subdivision}

For the last few decades, general and form subdivisions have been coded in the same way (using $\$ \mathrm{x}$ ) in MARC, despite arguments and complaints against such practice. In 1995, however, the USMARC Advisory Group approved a proposal defining subfield $\$ \mathrm{v}$ for form subdivision. In 1999, the LC began to identify form subdivisions with the new code. All of these have influenced old bibliographic records as well as new ones. For new items, the form subdivisions will be coded with $\$ \mathrm{v}$, but fixing millions of older item records, which lack explicit form subdivision coding, is a daunting task. Retrospective conversion for form subdivisions would require authority control processing specifications developed and tested. O'Neill and his colleagues (2001) describe a project for which an algorithm is developed to automatically identify form subdivisions coded as general subdivisions. The algorithm has proven to be a big success. With a low error rate (less than $0.1 \%$ ), the algorithm will help accurately convert general subdivisions $(\$ \mathrm{x})$ to form subdivisions $(\$ \mathrm{v})$ in old records.

\section{Faceted Subject Headings}

Subject cataloging using controlled vocabulary is an effective way of providing subject access, but is also known to be a difficult system to use. A more efficient and easier way of providing subject access is called for, especially in the networked environment to which naive users with diverse backgrounds are drawn. In response to such needs, OCLC has developed Faceted Application of Subject Terminology (FAST). FAST is a revolutionary schema based on LCSH and developed to make subject access easier for individuals with minimal training and experience. Unlike LCSH, it uses a postcoordinated faceted vocabulary, which is especially effective in an online environment. Chan and others (Chan et al. 2001) provide a good description of FAST and its plans.

\section{Subject Headings in Multiple Languages and Systems}

Another exciting trend in subject cataloging is the development of subject heading lists integrating headings in different languages or in different systems. Clavel-Merrin (2000) describes research on multilingual subject heading systems. A pilot study was conducted to establish equivalents among RAMEAU (a French subject heading system), SWD/RSWK (a German subject heading system), and LCSH (an English subject heading system) in selected subject areas. Based on the findings, the Multilingual Access to Subjects (MACS) prototype has been developed, providing mechanisms for the establishment of links between subject headings in different languages. It will allow users to browse and enter search terms in their own language and retrieve relevant resources regardless of indexing languages used for the resources. Landry (2001) offers a detailed description of the MACS prototype interface. 
There have been somewhat related but different efforts in vocabulary mapping between different subject heading systems in the same language. Roe (2001) describes efforts made in mapping between LCSH and Sears subject headings. This kind of project will help improve subject access to the collections of library consortia using different subject heading systems.

\section{Problems}

In addition to new developments, subject cataloging still has to deal with persistent problems. Inconsistency in subject cataloging (due to either differences in subject analyses or misinterpretation of cataloging rules), cultural bias in subject heading systems, and challenges in providing subject access to nonbook materials and fiction are some examples.

Shoham and Kedar (2001) report findings of their study on the inter-indexer consistency in subject cataloging. They make suggestions for facilitating the subjectcataloging process and improving the consistency in subject cataloging. Olson and Schlegl (2001) discuss problems of the systems used for providing subject access, such as classification and subject heading systems. They argue that topics and structures in subject heading systems do not accurately reflect reality, but are biased. Wilk and others (2001) support Olson and Schlegl's claim by showing that LCSH is a politically biased and Christian-oriented system. Wilk and his colleagues attest that LCSH is not specific enough for a large and varied Judaica and Israeli collection.

Nonbook materials have unique characteristics and cataloging them is always a challenge. Subject cataloging of such materials is not an exception. Ostrove (2001) reports problems in using LCSH for providing subject access to music materials. In music, distinguishing between form/genre and topic is often difficult. She suggests that LCSH should be changed to make subject cataloging of music materials easier. Yee (2001) compares LCSH and Moving Image Genre-Form Guide (MIGFG), and concludes that LCSH may be more useful than MIGFG even for providing genre/form access to moving and broadcast materials, although some improvement should be made in LCSH.

Fiction also may require special treatment when it comes to subject cataloging. Hayes (2001) examines a number of literary critiques/reviews to find out whether literary criticism can be a useful source for subject cataloging and what aspects of literature (e.g., denotative, connotative) would be feasible as subject access. Based on findings, she suggests some guidelines in providing subject access to imaginative works. Frierson-Adams (2002) provides specific guidelines for juvenile monographs including fiction.

\section{Cataloging Nonbook Materials}

Cataloging nonbook materials requires special knowledge and skills because such materials have unique characteristics due to their formats and contents. In 2000-2001, Cataloging and Classification Quarterly devoted its two issues (vol. 31, nos. 2-3/4) to the cataloging of nonbook materials. In this section, literature on cataloging music and other sound recordings, videorecordings, three-dimensional artifacts, and kits is reviewed. Following the literature review, issues related to current practices and history of cataloging nonbook materials are discussed.

\section{Music and Nonmusic Sound Recordings}

Simpkins (2001) provides detailed guidelines on cataloging popular music recordings. His article describes the entire cataloging process for popular music, including descriptive and subject cataloging but not classification. McBride (2000) addresses a rather specific problem in the MARC coding of music recordings. He examines $04 \mathrm{x}$ fields of the MARC format for music and discusses problems in the conception and design of the fields. He makes suggestions for improving access to music materials and concludes that links between appropriate fields would help improve retrieval of music items. Prochazka (2002), after analyzing current bibliographic records of music manuscripts and other related materials, has found that descriptive cataloging and MARC coding are not done in a consistent manner. He calls for more consistent and clear guidelines. Freeborn (2001) offers brief guidelines on cataloging nonmusic sound recordings.

\section{Videorecordings, Three-Dimensional Artifacts, and Kits}

Weitz (2001) provides some guidelines on cataloging videorecordings, with an emphasis on the areas in which catalogers may often encounter problems. Ho (2001) reports survey results on how faculty and graduate students search for videorecordings. Providing details of the findings, she suggests that more access points should be provided for videorecordings. Nancy Olson provides guidelines on cataloging 3-D materials (Olson 2001c) and also on cataloging kits (Olson 2001b).

\section{Cataloging Practice in Different Types of Libraries}

Chung (2001) and Piepenburg (2001) describe how audiovisual (AV) materials are cataloged in public and school libraries respectively. Piepenburg (2001) also offers some tips that can help school librarians in descriptive cataloging and MARC coding of AV materials. Boehr and Horan (2001) describe the 
National Library of Medicine's (NLM) current cataloging practice of nonprint materials.

Letarte (2001) surveyed school library media specialists to find out how school library media centers organize Internet resources. She has found that most of the school library media centers provide selected Web resources through bookmark files they created for students to use. Cataloging electronic resources, however, is not done in a consistent manner, does not follow standard rules, and seldom uses MARC fields that would be useful to school library collections.

\section{History of Cataloging Nonbook Materials}

Weihs (2001) provides a quite comprehensive history of cataloging nonbook materials. Evolution of terminology (e.g., nonbook, nonprint) and changes in rules, standards, and practices (e.g., AACR, ISBD, metadata, General Material Designation (GMD), main entry, form subdivisions, and subject analysis) are portrayed with reference to important events in the context of cataloging nonbook materials.

\section{Electronic Resources and Metadata}

As technology advances rapidly, bibliographic items have been published in increasingly diverse forms. Disks in different formats, interactive multimedia, and Web pages are some of the examples. Campbell (2001) points out that some unique genres (document types) are only applicable to digital resources like the Web, but not to traditional print resources (and vice versa). For instance, boundaries in document types or editions are blurred and more difficult to establish in electronic resources than in print. Campbell (2001) urges that clear, standard guidelines are needed for helping users as well as catalogers.

In order to catch up on these new developments, cataloging rules have undergone more frequent and drastic changes than ever (Sandberg-Fox 2001a). Nancy Olson (2001a) summarizes what has been going on in the cataloging field to accommodate electronic resources in new formats. After the publication of ISBD for Electronic Resources in 1997, the Committee on Cataloging: Description and Access (CC:DA) appointed a task force to examine areas 3 and 5 of chapter 9 , and to make recommendations at the 2002 ALA Conference about the location of information on remote access files. In her article, Olson (2001a) describes the rules new to chapter 9 of AACR2 and discusses both the new rules and the unchanged rules that are applicable to the cataloging of remote access electronic resources. For more details on the changes made in chapter 9, AACR2r (2002) itself is the best source to consult.
In 2000, the Library of Congress hosted a conference on bibliographic control for the new millennium. During the conference, several issues related to cataloging electronic resources were discussed. Sandberg-Fox (2001b) summarizes what was presented in the conference. Her report briefly describes presentations on current library standards for bibliographic control, such as faceted LCSH, Z39.50 interoperability, and DDC for organizing Web resources; she also describes presentations on future directions. Sandberg-Fox (2001b) also recapitulates studies comparing the effectiveness of different metadata sets and proposals on the cataloging of online serials. A year later, another international conference on electronic resources was held in Italy, and Plassard (2002) summarizes different issues discussed in the conference.

Many new ideas, standards, and projects have been launched in an attempt to make the organization of electronic resources easier and more efficient. Although some exciting ideas and projects are in progress, some concerns about the future directions in cataloging of electronic resources remain. Gorman (2001) is one of the individuals concerned about a rather fundamental issue: is it worth cataloging Internet resources? He argues that librarians should select only those worthy of cataloging and catalog fully the selected resources. He also asserts that cataloging electronic resources should be done following standard rules in order to facilitate an efficient information retrieval. Describing different approaches to authority control, Vellucci (2000) underscores the importance of authority control in applying metadata schemes, which somewhat concurs with Gorman's view. These positions are significantly different from those who are trying to make the metadata easier and simpler to use without any reinforced application of standard rules, but these differing positions deserve a serious consideration.

\section{Dublin Core and Other Metadata Schemes}

Although there are many different metadata schemes available for different kinds of collections, they are not widely used. Nowick (2002) investigates how metatags are used by Web authors. After examining a number of Web pages, she has found that several tags including "keywords" and "description" often were left unused. Drott's study (2002) has generated the same findings. Nowick (2002) speculates that this is due to lack of education and suggests that the use of metatags should be promoted and encouraged more aggressively.

Greenberg (2001) examines some of the currently available metadata schemas that can be used for organizing image information and finds that all of these consist of elements in different functional categories, such as object discovery, use, authentication, and administration, although 
the number and proportion of elements in these categories vary depending on the schema. She suggests further exploration of the role of functional metadata classes in designing schemas and understanding users' needs, since networked communication introduces a new information environment.

Among different metadata schemes, Dublin Core (DC) seems to be the one most widely accepted and used. DC is a metadata element set (with fifteen elements) developed for describing Internet resources. It was initiated by OCLC in 1996. In 2000, DC got formal recognition by the Center for European Normalization (CEN), the European standardization body. In 2001, DC was ratified under the auspices of the National Information Standards Organization (NISO) as American National Standards Institute (ANSI) standard Z39.85. More details on the recent development in DC are well described in Dekkers's and Weibel's article (2002).

Polydoratou and Nicholas (2001) conducted a survey of information professionals and confirm that DC is the most widely used metadata in general, while MARC is popular in the research sector. Guinchard (2002) reports the results of her e-mail survey on who uses DC and why and how it is used. Her article provides a snapshot of current implementation and usage of DC: what elements are frequently used, what other metadata elements and qualifiers are used, what encoding formats are used, what kind of challenges are encountered, etc. Allen (2001) reports some problems in using DC for organizing digital images of maps. He raises fundamental questions, such as whether digital images should be treated as surrogates of the original, and how ephemerality of Internet resources should be handled. He also points out problems related to DC in CORC, including problems in map searching, in creating records with special letters, etc.

\section{Dublin Core Applications}

DC is applied to organizing electronic information even in the government sector. The Minnesota state government uses DC to provide effective tools for citizens to discover the environmental and natural resource information they need and to integrate access to diverse information resource types across multiple domains (Quam 2001). With an overview of metadata usage in various Government Information Locator Service (GILS) initiatives, Mullen (2001) reports the Texas State Library's application of DC in its Texas Record and Information Locator (TRAIL) service. Howarth (2001) introduces more cases in Canada, where DC is used along with GILS, including cases of Environment Canada's Green Lane (www.ec.gc.ca) and Canadian Health Network (www.canadian-health-network.ca). DC is also used for organizing educational mate- rials/resources (Richmond and Kartus 2001). Science Net, an educational project for $\mathrm{K}-12$, for example, uses DC along with DDC to organize its resources.

\section{Crosswalk}

As many different metadata schemes are used in different information systems, it seems imperative to make crosswalks among those databases possible so that users can find information across different databases without worrying about differences in the databases. To respond to such demand, a great deal of effort is going into making different metadata systems compatible. Chandrakar (2002) discusses the importance of crosswalks to DC and explains what has been done in India in order to make a crosswalk between the Common Information Format (CCF) and the Information and Library Network (INFLIBNET) metadata to DC. Chang (2001) describes efforts in mapping AACR2/MARC data fields to the Text Encoding Initiative (TEI) header's corresponding tags, started as early as 1994. TEI is a metadata scheme developed for humanities scholars. Moen (2001) introduces other ways of making it possible for different systems to communicate with each other. ANSI/NISO Z39.50 information retrieval protocol is one approach to cross locator searching; Open Archives Initiative (OAI) is another way of making crosswalks possible.

\section{CORC}

CORC is a project designed to encourage and enhance the description of Web resources. It started as a research project at OCLC in 1998. Its goal was to create a centralized database of Web resources through large-scale cooperation among libraries. The prototype service became available in 1999, and LC became an official participant in the same year. In 2000, CORC became a full OCLC service.

In 2001, Journal of Internet Cataloging published a special issue on CORC (JIC, vol. 4, no. 1/2). Several articles in the issue provide good background information on CORC. Edmunds's and Brisson's article (2001), for example, explains how CORC works and what the strengths and weaknesses are. They discuss problems with the automatic generation of DDC numbers and possible subject keywords based on a textual analysis of the site. They also make suggestions to improve CORC. Godby and Reighart (2001) focus on the WordSmith project, one of the features of CORC, and describe how WordSmith works to automatically supplement subject access terms for the Web documents in the CORC database. Childress (2001) also explains how CORC harvests metadata imbedded in the resource itself and how subject keywords and DDC numbers are generated based on the text analysis. Vizine-Goetz (2001a) describes how the DDC database has been 
enriched through vocabulary mapping between DDC and LCSH and how this has improved the ability of CORC users to employ classification in metadata records and pathfinders. Although not in the special issue, Senecal (2000) summarizes what CORC can do, describing different features of CORC.

Even though participation in the CORC project was voluntary, the number of participants grew continually. In 1999, LC decided to become one of the CORC participants, because of the cost-effectiveness and timeliness that CORC can offer (Hayes and Larson 2001). Most of the contributing participants of CORC are academic libraries (Connell and Prabha 2002). However, an increasing number of libraries in specific fields also adopt CORC to provide access to their specialized Web collection. Medical libraries use CORC to organize Web resources (Medeiros, McDonald, and Wrynn 2001), and art libraries use it to organize digital images (Hanlon and Copeland 2001). Hayes and Larson (2001) describe different LC projects that are using CORC (e.g., BeOnline, Web Preservation Project, and URL maintenance).

While CORC remains a convenient tool for organizing Web resources, it has some problems. Most participants are dissatisfied with automatic harvesting that extracts keywords from a digital document and uses an algorithm to assign subject headings and classification numbers. It is especially inadequate for art images because images tend to be accompanied by little or no description and even that is often abstract in nature (Hanlon and Copeland 2001). CORC also has problems in creating records with diacritics and special letters and in searching maps (Allen 2001). Jones (2001) points out problems that can occur when cataloging serials using CORC, because it apparently was developed for monographic resources. Many CORC users also complain about slow response time (Edmunds and Brisson 2001).

All these problems are confirmed in other surveys. Hsieh-Yee and Smith (2001a; 2001b) surveyed libraries that participated in the founders' phase of the CORC project. They wanted to know why these early participants chose to join CORC, how they used the system, and how they viewed their experiences with the project. The survey revealed that most of the libraries used CORC to apply traditional cataloging methods and standards to Internet resources rather than to experiment with description options for other resources, such as using DC. The libraries considered their CORC experience positive, but they also had several concerns. Their concerns were related to slow response time, client/server interface, and automatically generated subject terms and numbers.

Recently, CORC was absorbed into the Connexion service launched in 2002. Connexion is the new face of OCLC cataloging, providing one-stop access to integrated cataloging tools and to WorldCat. The initial release uses a browser interface for many functions found in OCLC's various cataloging services. Functions of the OCLC CORC service, CatExpress service, and other options, such as Dewey services, are all included in Connexion (OCLC 2002). For more information on Connexion, OCLC's Web site provides most of the related documents (www.oclc. org/connexion).

\section{International Cooperation}

The Program for Cooperative Cataloging (PCC), initiated in 1995, is an international cooperation effort aimed at expanding access to library collections by providing useful, timely, and cost-effective cataloging that meets mutually accepted standards of libraries around the world (Taylor 2000). It now consists of four components: Name Authority Cooperative (NACO), Subject Authority Cooperative (SACO), Bibliographic Cooperative (BIBCO), and Cooperative Online Serial (CONSER). Having grown out of cooperative activities involving LC and other U.S. libraries, PCC has been dominated by U.S. participants. Recently, however, increasing participation from non-U.S. countries has been observed in PCC, SACO, and NACO (Franks and Cristan 2000; Franks 2001). Byrum (2000) provides a good overview of international standardization efforts in cataloging, including PCC and IFLA activities. Parent (2000) describes IFLA's Section on Cataloging and its contributions to bibliographic control at the international level. Recent revisions in ISBD and FRBR are some examples. While encouraged by the increasing level of international cooperation, Parent (2000) points out some difficulties in such cooperative efforts, including the communication problem. She conjectures that the predominance of Anglo-American committee chairs in most programs, including the Bibliographic Control Division of IFLA, may be explained by the common usage of English in international meetings.

\section{Other Issues Cataloging Management}

Cataloging is one of the service areas that entails a high cost. Outsourcing is a solution that can reduce the cost, especially for libraries with limited resources. Lam (2001) reports an outsourcing experience using Innovative Interface's INNOPAC and Library Tech Inc. (LTI) for authority control.

In an effort to evaluate cataloging efficiency and effectiveness, McCain and Shorten (2002) surveyed academic libraries and developed measures based on multiple factors such as reported productivity, number of staff, task 
distribution, and quality measures. They suggest benchmark productivity levels for best practices, which could be used by libraries to assess their cataloging effectiveness and efficiency.

General management issues in different libraries are addressed and discussed in two Cataloging b Classification Quarterly issues published in 2000 (vol. 30, nos. 1, 2/3). The two special issues contain papers describing how cataloging and other related operations are managed in national libraries, special and academic libraries, and libraries around the world.

\section{Cataloging Education and Training}

With continual changes in cataloging principles and practices, cataloging education and training have become a challenge to educators as well as information professionals. What do we need to teach in school? How can we incorporate newly developed rules and standards in library and information science (LIS) curriculum more promptly? What about the training of catalogers? What should we do to help catalogers update their knowledge and skills so that they can remain competent?

Letarte and her colleagues (2002) conducted a survey to find out what knowledge and skills are considered valuable for entry-level academic librarians. Their survey of heads of reference and cataloging in academic libraries reveals that basic cataloging knowledge and skills are still very important for new librarians. More than half of the respondents believe that knowledge of LCSH, LCC, MARC, and AACR is essential, while they also recognize the usefulness of knowing HTML, DC, and other metadata schemes.

As part of an effort to incorporate newly developed standards in the LIS curriculum, Hsieh-Yee (2000) and Glaviano (2000) describe courses that they offered to introduce students to metadata used for organizing Internet resources and discuss their experience in teaching such courses. Howarth (2000) addresses the barriers that catalogers face in updating their knowledge and skills, and applauds the Serials Cataloging Cooperative Training Program's (SCCTP) role in training catalogers. SCCTP is a cooperative program that also provides standardized training materials and trained trainers in periodicals cataloging. Howarth (2000) and Hawkins (2001) recognize SCCTP as a good model for continuous professional development.

\section{Summary}

Current trends reflected in the literature published during the last two years can be summarized into two points. First, advances in technologies have forced continual changes in theories, standards, rules, and systems of cataloging and classification. AACR2r and ISBD have undergone significant changes to cope with the new forms of bibliographic items such as Web resources. Faceted subject headings have been introduced to facilitate information retrieval, especially in the online environment. As different metadata schemes developed in the 1980s and 1990s have been stabilized and adopted in numerous projects, metadata interoperability has become an important issue. All these changes seem to have stemmed from continuing technological development. Second, globalization has promoted bibliographic control, system development, and application at the international level, and it has also contributed to the increasing awareness of problems in existing systems. Issues related to Romanization have been raised more frequently as an increasing number of bibliographic items from foreign countries are being made available to users. Systems that can handle multiple languages have received more attention, and some of them are, in fact, under development. Harmonization between different MARC systems in different countries has been actively sought and partially realized. The FRBR model has been developed to identify essential elements of bibliographic records, based on the user's information needs and the collection characteristics. Cultural biases in existing systems have been more openly discussed, and different approaches to developing culture-neutral systems are being formulated. All these developments can be attributed to the increasing level of internationalization. Technology and globalization likely will remain as influential forces of change in the future as well.

\section{Works Cited}

Alexander, Arden, and Tracy Meehleib. 2001. The thesaurus for graphic materials: Its history, use, and future. Cataloging \& Classification Quarterly 31 (3/4): 189-212.

Algier, Aimee. 2001. The dynamic Caribbean: A change for the Library of Congress. Cataloging \& Classification Quarterly 32 (1): 29-38.

Allen, David Yehling. 2001. Using the Dublin Core with CORC to catalog digital images of maps. Journal of Internet Cataloging $4(1 / 2): 163-77$.

Anglo-American cataloguing rules. 2d ed., 2002 rev. Chicago: ALA.

Arsenault, C. 2001. Word division in the transcription of Chinese script in the title fields of bibliographic records. Cataloging \& Classification Quarterly 32 (3): 109-27.

Ayres, F. H. 2001. Authority control simply does not work. Cataloging \& Classification Quarterly 32 (2): 49-59.

Beall, Jeffrey. 2001. Publishers' errors make cataloger [sic]: An analysis of the error indicators [sic] and [i.e.] in cataloging. Cataloging \& Classification Quarterly 32 (3): 87-107.

Beghtol, Clare. 2002. A proposed ethical warrant for global knowledge representation and organization systems. Journal of Documentation 58 (5): 507-32. 
Boehr, Diane L., and Meredith L. Horan. 2001. Non-print media at the National Library of Medicine. Cataloging \& Classification Quarterly 31 (3/4): 341-54.

Bolander, Robert C. 2001. Dublin Core metadata element set approved as ANSI standard Z39.85-2001. OCLC Newsletter (Nov./Dec.): 19-20.

Bowman, J. H. 2001. Sic Catalog syndrome: Title page transcription as a barrier to retrieval. Cataloging \& Classification Quarterly 32 (1): 39-54.

Byrum, John Donald, Jr. 2000. The emerging global bibliographic network: The era of international standardization in the development of cataloging policy. Library Resources \& Technical Services 44 (3): 114-21.

Campbell, D. Grant. 2001. Straining the standards: How cataloging Websites for curriculum support poses fresh problems for Anglo-American Cataloging Rules. Journal of Internet Cataloging 3 (1): 79-92.

Chan, Lois Mai, Eric Childress, Rebecca Dean, Edward T. O'Neill, and Diane Vizine-Goetz. 2001. A faceted approach to subject data in the Dublin Core metadata record. Journal of Internet Cataloging 4 (1/2): 35-47.

Chandrakar, Rajesh. 2002. CCF and INFLIBNET standard metadata to Dublin Core crosswalk. Journal of Internet Cataloging 5 (3): 33-57.

Chang, Sheau-Hwang. 2001. The implications of TEI. OCLC Systems \& Services 17 (3): 101-3.

Childress, Eric. 2001. Crosswalking metadata in the OCLC CORC service. Journal of Internet Cataloging 4 (1/2): 81-88.

Chung, Heeja Hahn. 2001. User-friendly audiovisual material cataloging at Westchester County public library system. Cataloging \& Classification Quarterly 31 (3/4): 313-25.

Clavel-Merrin, Genevieve. 2000. The need for cooperation in creating and maintaining multilingual subject authority files. International Cataloguing and Bibliographic Control 29 (3): $43-45$.

Connell, Tschera Harkness, and Chandra Prabha. 2002. Characteristics of resources represented in the OCLC CORC database. Library Resources \& Technical Services 46 (2): $39-49$.

Crawford, Libbie. 2001. People, Place \& Things introduced. OCLC Newsletter (Nov./Dec.): 36-37.

Dekkers, Makx, and Stuart L. Weibel. 2002. Dublin Core metadata initiative progress report and workplan for 2002. D-Lib Magazine 8 (2): 1-9. Accessed Dec. 1, 2002, www.dlib.org/ dlib/february02/weibel/02weibel.html.

Drott, M. Carl. 2002. Indexing aids at corporate Web sites: The use of robots.txt and META tags. Information Processing \& Management 38 (2): 209-19.

Edmunds, Jeff, and Roger Brisson. 2001. Cataloging in CORC: A work in progress. Journal of Internet Cataloging 4 (1/2): 89-109.

Ellero, Nadine P. 2002. Panning for gold: Utility of the World Wide Web for metadata and authority control in special collection. Library Resources \& Technical Services 46 (3): 79-91.

Fiander, David J. 2001. Applying XML to the bibliographic description. Cataloging \& Classification Quarterly 33 (2): 17-28.

Franks, Anthony R. D. 2001. International participation in the Program for Cooperative Cataloging: Present status.
International Cataloguing and Bibliographic Control 30 (2): 23-26.

Franks, Anthony R. D., and Ana Cristan. 2000. International cooperation in the Program for Cooperative Cataloging: Present and prospect. Cataloging \& Classification Quarterly 30 (4): 37-50.

Freeborn, Robert B. 2001. Cataloging non-music sound recordings. Cataloging \& Classification Quarterly 31 (2): 37-51.

Frierson-Adams, Vickie. 2002. Cataloging juvenile monographs in an academic library. Technical Services Quarterly 20 (1): 39-47.

Glaviano, Cliff. 2000. Teaching an information organization course with Nordic DC metadata creator. OCLC Systems d Services 16 (1): 33-40.

Godby, Carol Jean, and Ray Reighart. 2001. Terminology identification in a collection of Web resources. Journal of Internet Cataloging 4 (1/2): 49-65.

Godby, Carol Jean, and Diane Vizine-Goetz. 2000. ISKO participants discuss ways librarianship can improve responsiveness of the Web. OCLC Newsletter (Sept./Oct.): 22-25.

Gorman, Michael. 2001. Bibliographic control or chaos: An agenda for national bibliographic services in the 21st century. IFLA Journal 27 (5/6): 307-13.

Greenberg, Jane. 2001. A quantitative categorical analysis of metadata elements in image-applicable metadata schemas. Journal of the American Society for Information Science and Technology 52 (11): 917-24.

Guinchard, Carolyn. 2002. Dublin Core use in libraries: A survey. OCLC Systems \& Services 18 (1): 40-50.

Hanlon, Ann, and Ann Copeland. 2001. Using the Dublin Core to document digital art: A case study. Journal of Internet Cataloging 4 (1/2): 149-61.

Hawkins, Les. 2001. Cataloging Web-based integrating resources. Serials Review 27 (3/4): 93-96.

Hayes, Allene, and Carolyn Larson. 2001. Use of OCLC's CORC at the Library of Congress. Serials Review 27 (2): 41-48.

Hayes, Susan M. 2001. Use of popular and literary criticism in providing subject access in imaginative literature. Cataloging \& Classification Quarterly 32 (4): 71-97.

Heijligers, Ton. 2001. Structures of corporate name headings: Final report of the Working Group on the Revision of FSCH (IFLA Section on Cataloging). International Cataloguing and Bibliographic Control 30 (3): 50-54.

Hickey, Thomas B., Edward T. O’Neill, and Jenny Toves. 2002. Experiments with the IFLA Functional Requirements for Bibliographic Records (FRBR). D-Lib Magazine 8 (9): 1-13. Accessed Dec. 1, 2002, www.dlib.org/dlib/september02/ hickey/09hickey.html.

Hinton, Mellissa J. 2002. On cataloging Internet resources: Voice from the field. Journal of Internet Cataloging 5 (1): 53-67.

Hirons, Jean, Karen Darling, and Wendy Robertson. 2001. We're heading for the barn now! An update on the revisions to $\operatorname{ISBD}(\mathrm{S})$ and AACR2 Rules for serials cataloging. Serials Librarian 40 (3/4): 381-92.

Ho, Jeannette. 2001. Faculty and graduate student search patterns and perceptions of videos in the online catalog. Cataloging \& Classification Quarterly 33 (2): 69-88.

Horn, Marguerite E. 2002. "Garbage" in, "refuse and refuse disposal" out: Making the most of the subject authority file in the 
OPAC. Library Resources \& Technical Services 46 (3): 92-102.

Howarth, Lynne C. 2000. (Re)Making the serials cataloger: The SCCTP within an educational framework. Cataloging \& Classification Quarterly 30 (4): 29-36.

— 2001. Report on the metadata workshop, IFLA 2000 conference. International Cataloguing and Bibliographic Control 30 (3): 55-56.

Hsieh-Yee, Ingrid. 2000. Organizing Internet resources: Teaching cataloging standards and beyond. OCLC Systems \& Services 16 (3): 130-43.

Hsieh-Yee, Ingrid, and Michael Smith. 2001a. The CORC experience: Survey of founding libraries. Part 1. OCLC Systems b Services 17 (3): 133-40.

. 2001b. The CORC experience: Survey of founding libraries. Part 2. OCLC Systems \& Services 17 (4): 166-77.

IFLA. 1998. FRBR (Functional Requirements for Bibliographic Records): Final report. UBCIM Publications-New Series. Vol. 19. Accessed Dec. 1, 2002, www.ifla.org/VII/s13/frbr/ frbr.htm.

1999. ISBD(ER): International Standard Bibliographic Description for Electronic Resources. Accessed Dec. 1, 2002, www.ifla.org/VII/s13/pubs/isbd3.htm.

- 2002a. ISBD $(\mathbf{M})$ : International Standard Bibliographic Description for Monographic Publications. Accessed Dec. 1, 2002, www.ifla.org/VII/s13/pubs/isbd m0602.pdf.

_ 2002b. ISBD $(\mathrm{CR})$ : International Standard Bibliographic Description for Serials and Other Continuing Resources. München: UBCIM Publications.

Iwe, Josephine I. 2001. Linguistics and information processing: Provision of syntactic and semantic consistency in the language of Library of Congress Subject Headings pertaining to literature and librarianship: A comparative analysis. Cataloging \& Classification Quarterly 32 (2): 107-26.

Johnson, Bruce C. 2001. XML and MARC: Which is right? Cataloging \& Classification Quarterly 32 (1): 81-90.

Jones, Wayne. 2001. Dublin Core and serials. Journal of Internet Cataloging 4 (1/2): 143-48.

Kellsey, Charlene. 2001. Trends in source of catalog records for European monographs 1996-2000: A preliminary study of Italian monographs. Library Resources \& Technical Services 45 (3): 123-26

- 2002. Cooperative cataloging, vendor records, and European language monographs. Library Resources of Technical Services 46 (3): 105-10.

Lam, Vinh-The. 2001. Outsourcing authority control: Experience of the University of Saskatchewan Libraries. Cataloging \& Classification Quarterly 32 (4): 53-69.

Landry, Patricia. 2001. The MACS project: Multilingual access to subjects (LCSH, RANEAU, SWD). International Cataloguing and Bibliographic Control 30 (3): 46-49.

Lawson, Dawn. 2001. You've come a long way, Dewey! OCLC Newsletter (Nov./Dec.): 34-35.

Le Boeuf, Patrick. 2001. FRBR and further. Cataloging \& Classification Quarterly 32 (4): 15-52.

Letarte, Karen. 2001. The school library media center in the digital age: Issues in the cataloging of electronic resources. Journal of Internet Cataloging 3 (1): 13-40.
Letarte, Karen M., Michelle R. Turvey, Dea Borneman, and David L. Adams. 2002. Practitioner perspectives on cataloging education for entry-level academic librarians. Library Resources \& Technical Services 46 (1): 11-22.

Madison, Olivia M. A. 2000. The IFLA Functional Requirements for Bibliographic Records: International standards for universal bibliographic control. Library Resources \& Technical Services 44 (3): 153-59.

Manning, Ralph W. 2000. The Anglo-American Cataloguing Rules and their future. Library Resources \& Technical Services 44 (3): 129-34.

Martin, Cheryl, and Wayne Daniels. 2001. Dewey applications for the simple arrangement of a link library: The case of Science Net. Journal of Internet Cataloging 3 (1): 66-77.

Martinez-Arellano, Filiberto F., and Orlanda A. Yanez Garrido. 2000. Classification systems used in Latin American libraries. Cataloging \& Classification Quarterly 30 (1): 123-36.

McBride, Jerry L. 2000. Faceted subject access for music through USMARC: A case for linked fields. Cataloging \& Classification Quarterly 31 (1): 15-30.

McCain, Cheryl, and Jay Shorten. 2002. Cataloging efficiency and effectiveness. Library Resources \& Technical Services 46 (1): $23-31$.

McCallum, Sally H. 2000. Harmonization of USMARC, CAN/MARC, and UKMARC. Library Resources d Technical Services 44 (3): 135-40.

- 2002. Mapping as a solution? International Cataloguing and Bibliographic Control 31 (3): 48-50.

McKiernan, Gerry. 2002a. News from the field. Journal of Internet Cataloging 5 (3): 79-95.

- 2002b. News from the field. Journal of Internet Cataloging 5 (1): 81-98.

Medeiros, Norm, Robert F. McDonald, and Paul Wrynn. 2001. Utilizing CORC to develop and maintain access to biomedical Web sites. Journal of Internet Cataloging 4 (1/2): 111-21.

Mitchell, Joan. 2001. Dewey Decimal Classification: 125 and still growing. OCLC Newsletter (Nov./Dec.): 27-29.

Moen, William E. 2001. The metadata approach to accessing government information. Government Information Quarterly 18: 155-65.

Mullen, Allen. 2001. GILS metadata initiatives at the state level. Government Information Quarterly 18: 16780.

Nowick, Elaine A. 2002. Use of META tags for Internet documents. Journal of Internet Cataloging 5 (1): 69-75.

OCLC. 2002. OCLC Connexion. Accessed Dec. 1, 2002, www.oclc.org/connexion.

Oh, Dong-Geun, and Ji-Suk Yeo. 2001. Suggesting an option for DDC class religion (200) for nations in which religions diversity predominates. Knowledge Organization 28 (2): 75-84.

Olson, Hope. 2001. Sameness and difference: A cultural foundation of classification. Library Resources \& Technical Services 45 (3): 115-22.

Olson, Hope A., and Rose Schlegl. 2001. Standardization, objectivity, and user focus: A meta-analysis of subject access critiques. Cataloging \& Classification Quarterly 32 (2): $61-80$

Olson, Nancy B. 2001a. Cataloging remote electronic resources. Cataloging \& Classification Quarterly 31 (2): 101-37. 
2001b. Cataloging kits. Cataloging \& Classification Quarterly 31 (3/4): 151-57.

-2001c. Cataloging three-dimensional artefacts and realia. Cataloging \& Classification Quarterly 31 (3/4): 139-50.

O’Neill, Edward T., Lois Mai Chan, Eric Childress, Rebecca Dean, Lynn M. El-Hoshy, and Diane Vizine-Goetz. 2001. Form subdivisions: Their identification and use in LCSH. Library Resources \& Technical Services 45 (4): 187-97.

Ostrove, Geraldine E. 2001. Music subject cataloging and form/genre implementation at the Library of Congress. Cataloging \& Classification Quarterly 32 (2): 91-106.

Parent, Ingrid. 2000. IFLA Section on Cataloguing: "Why in the world?" Library Resources \& Technical Services 44 (3): 146-52.

Piepenburg, Scott. 2001. Cataloging AV in school libraries. Cataloging \& Classification Quarterly 31 (3/4): 327-40.

Plassard, Marie-France. 2002. International conference on electronic resources, definition, selection and cataloguing, Rome, 26-28 November 2001. International Cataloguing and Bibliographic Control 31 (2): 37-38.

Polydoratou, Panayiota, and David Nicholas. 2001. Familiarity with and use of metadata formats and metadata registries amongst those working in diverse professional communities within the information sector. Aslib Proceedings 53 (8): 309-24

Prochazka, David. 2002. Cataloging contemporary music manuscripts and related materials: A look at Library of Congress practices: Part II. Technical Services Quarterly 20 (1): 1-12.

Quam, Eileen. 2001. Informing and evaluating a metadata initiative: Usability and metadata studies in Minnesota's Foundations Project. Government Information Quarterly 18: 181-94.

Rafferty, Pauline. 2001. The representation of knowledge in library classification schemes. Knowledge Organization 28 (4): 180-91.

Richmond, Cate, and Ebe Kartus. 2001. Providing access to course material at Deakin University. Journal of Internet Cataloging 3 (2/3): 203-16.

Roe, Sandra K. 2001. Subject access vocabularies in a multi-type library consortium. Cataloging \& Classification Quarterly 33 (2): $55-67$.

Ruan, Lian. 2001. Providing better subject access to nonprint fire emergency materials for Illinois firefighters. Cataloging \& Classification Quarterly 31 (3/4): 213-35.

Saeed, Hamid, and Abdus Sattar Chaudhry. 2002. Using Dewey Decimal Classification scheme (DDC) for building taxonomies for knowledge organization. Journal of Documentation 58 (5): 575-83.

Saeed, Hamid, and Abdus Sattar Chaudhry. 2001. Potential of bibliographic tools to organize knowledge on the Internet: The use of Dewey Decimal Classification scheme for organizing Web-based information resources. Knowledge Organization 28 (1): 17-26.

Sandberg-Fox, Ann M. 2001a. The microcomputer revolution. Cataloging \& Classification Quarterly 31 (2): 85-99.
- 2001b. Report on the Library of Congress Conference on bibliographic control for the new millennium: Confronting the challenges of the networked resources and the Web, Nov. 15-17, 2002, Washington, D.C. Cataloging \& Classification Quarterly 32 (2): 35-48.

Satija, Mohinder P. 2000. Library classification: An essay in terminology. Knowledge Organization 27 (4): 221-29.

Senecal, Kristin. 2000. The twofold promise of the CORC project. OCLC Systems \& Services 16 (2): 84-90.

Shedenhelm, Laura D., and Bartley Burk. 2001. Book vendor records in the OCLC database: Boon or bane? Library Resources \& Technical Services 45 (1): 10-19.

Shelton, Judith M. 2000. Library of Congress' Class L: Education, table L7-an expansion for local use. Cataloging \& Classification Quarterly 31 (1): 31-42.

Shoham, Snunith, and Rochelle Kedar. 2001. The subject cataloging of monographs with the use of keywords. Cataloging \& Classification Quarterly 33 (2): 29-54.

Simpkins, Terry. 2001. Cataloging popular music recordings. Cataloging \& Classification Quarterly 31 (2): 1-35.

Tabb, Winston. 2001. The Library of Congress and the DDC. OCLC Newsletter (Nov./Dec.): 32-33.

Taylor, Arlene G. 2000. Wynar's introduction to cataloging and classification. 9th ed. Englewood, Colo.: Libraries Unlimited.

Tennant, Roy. 2001. Different paths to interoperability. Library Journal 26 (3): 118-19.

Tillett, Barbara B. 2000. Authority control at the international level. Library Resources \& Technical Services 44 (3): 168-72.

Vellucci, Sherry L. 2000. Metadata and authority control. Library Resources \& Technical Services 44 (1): 33-43.

Vizine-Goetz, Diane. 2001a. Dewey in CORC: Classification in metadata and pathfinders. Journal of Internet Cataloging 4 (1/2): 67-80.

- 2001b. Dewey research: New uses for the DDC. OCLC Newsletter (Nov./Dec.): 24-26.

Wang, Yewang. 2000. A look into Chinese persons' names in bibliography practice. Cataloging \& Classification Quarterly 31 (1): 51-81.

Weihs, Jean. 2001. A somewhat personal history of nonbook cataloging. Cataloging \& Classification Quarterly 31 (3/4): 159-88.

Weinberg, Bella Hass, and Joan M. Aliprand. 2002. Closing the circle: Automated authority control and the multiscript YIVO catalog. International Cataloguing and Bibliographic Control 31 (3): 44-47.

Weitz, Jay. 2001. Video recording cataloging: Problems and pointers. Cataloging \& Classification Quarterly 31 (2): 53-83.

Wilk, David, Shlomo Rotenberg, Sarah Schacham, Gita Hoffman, and Shifra Liebman. 2001. Problems in the use of Library of Congress Subject Headings as the basis for Hebrew Subject Headings in the Bar-Ilan University library. International Cataloguing and Bibliographic Control 30 (3): 43-46.

Yee, Martha M. 2001. Two genre and form lists for moving and broadcast materials: A comparison. Cataloging d Classification Quarterly 31 (3/4): 237-95. 